\title{
Territórios de violência: análise socioespacial dos homicídios em São José dos Campos, SP, Brasil
}

\author{
Urban sprawl and violence: socio-spatial analysis of \\ homicides in the city of São José dos Campos, SP, Brazil
}

Paula Vilhena Carnevale Vianna [a,b] [D, Cilene Gomes [c] [D],

Rene Novaes [d] [D], Arlindo Albergaria Jr. [e] [D]

[a] Universidade do Vale do Paraíba (Univap), São José dos Campos, SP, Brasil

[b] Universidade Anhembi Morumbi, Curso de Medicina, São José dos Campos, SP, Brasil

[c] Universidade do Vale do Paraíba, Programa de Pós-Graduação em Planejamento Urbano e Regional (PPGPLUR), São José dos Campos, SP, Brasil

[d] Instituto Nacional de Pesquisas Espaciais (LADES/INPE), Laboratório de Aplicação de Dados Espaciais em apoio à Sociedade, São José dos Campos, SP, Brasil

[e] Centro de Altos Estudos de Segurança, São Paulo, SP, Brasil

Como citar: Vianna, P. V. C., Gomes, C., Novaes, R., \& Albergaria Jr., A. (2021). Territórios de violência: análise socioespacial dos homicídios em São José dos Campos, SP, Brasil. urbe. Revista Brasileira de Gestão Urbana, v.13, e20200031. https://doi.org/10.1590/2175-3369.013.e20200031

\section{Resumo}

A perspectiva territorial de análise de dados favorece o planejamento de políticas sociais equânimes. Este artigo analisa a distribuição socioespacial dos homicídios dolosos em São José dos Campos, sede de Região Metropolitana em São Paulo, Brasil, entre 2015 e 2017, considerando os processos históricos de urbanização e estruturação do espaço urbano. 0 estudo é exploratório, fundamentado na análise estatística descritiva e georreferenciada dos homicídios dolosos ocorridos no município entre 2015 e 2017. Houve tendência de redução da taxa global e concentração espacial nas zonas de piores indicadores sociais e expansão urbana recente, impulsionada por políticas habitacionais. A pesquisa alerta para o papel das políticas públicas habitacionais na criação de territórios de violência.

Palavras-chave: Espraiamento urbano. Violência. Homicídios. São José dos Campos. Políticas públicas.

\begin{abstract}
The risk of violent deaths tends do increase in areas of precarious infrastructure. This paper aims to analyze the socio-spatial distribution of homicides in São José dos Campos (SJC), located in the Metropolitan Region in the
\end{abstract}

PVCV é médica, doutora em Medicina Preventiva, e-mail: paula.cvianna@anhembi.br

CG é docente pesquisadora, doutora em Geografia Humana, e-mail: cilenegomes2011@gmail.com

RN é geógrafo, mestre em Planejamento Urbano e Regional, e-mail: rene.junior@inpe.br

AAJ é major da polícia militar, doutorando em Ciências Policiais de Segurança e Ordem, e-mail: albergar@policiamilitar.sp.gov.br 
state of São Paulo, Brazil, from 2015 to 2017, considering the urbanization and urban space structuring processes. The exploratory study, based on secondary data, is grounded on descriptive statistical and spatial analysis of the homicides that occurred in SJC between 2015 and 2017. The overall rate tended to decline in the period and the deaths occurred mainly in two zones of poorer social indicators and recent urban sprawl boosted by housing policies. The research is a warning against the role of public policies in creating violent territories.

Keywords: Urban sprawl. Violence. Homicides. São José dos Campos. Public policies.

\section{Introdução}

Em suas múltiplas manifestações e ocorrências, a violência permeia a vida social. Os homicídios são um indicador desse fenômeno. A relativa facilidade de coleta de informação e padronização dos dados possibilita comparações temporais e em escalas geográficas.

Questão social prioritária na América Latina, que abriga um décimo da população mundial e concentra um terço dos homicídios (UNODC, 2013), o tema é objeto de interesse no campo acadêmico, que procura compreender o fenômeno (Briceño-Leon, 2012; Beato, 2010; Corrêa e Lobo, 2019; Adorno e Nery, 2019) e no das práticas sociais, orientando a formulação e implementação de políticas e intervenções públicas. Por ser fenômeno multifacetado, as intervenções são observáveis em diversos campos, tais como as propostas no âmbito da segurança pública (Madeira \& Rodrigues, 2015), do planejamento urbano, da saúde (Brasil, 2002), e experiências que articulam políticas públicas e participação social (Silva et al., 2018).

Estudos realizados nas cidades latino-americanas indicam a importância das dinâmicas sóciohistóricas que constituíram as cidades, associadas à natureza das instituições de governo e agravadas pelas iniquidades urbanas (Briceño-Leon, 2012). Pobreza, desigualdade e fragilidade institucional relacionam-se ao aumento de homicídios em séries históricas, em comparações entre cidades e países da região da América Latina (Briceño-Leon, 2012). Intervenções bem-sucedidas, apoiadas no fortalecimento institucional e no envolvimento da comunidade (Silva et al., 2018, Beato, 2010), parecem confirmar essas associações.

As mortes por agressão não se distribuem de forma aleatória no espectro sociodemográfico ou no espaço (Waiselfisz, 2016; IPEA, 2018). 0 risco da morte letal no Brasil é maior entre homens jovens e negros, que são, igualmente, os principais perpetradores da violência em sua forma letal (Soares Filho, 2011; Araujo et al., 2010; Waiselfisz, 2016; IPEA, 2018). 0 uso de armas de fogo (Waiselfisz, 2016) e o tráfico de drogas são variáveis frequentemente associadas aos homicídios em homens jovens (Lira, 2017; Corrêa e Lobo, 2019; Adorno e Nery, 2019).

$\mathrm{Na}$ escala intraurbana, o risco tende a ser maior em áreas de indicadores socioeconômicos desfavoráveis e precária infraestrutura urbana (Lira, 2017). Beato (2010) chama a atenção para a previsibilidade e concentração espacial dos homicídios, e a consequente necessidade de identificar os locais de ocorrência para planejar projetos de intervenção.

Como apontam autores clássicos no campo das ciências sociais aplicadas e do planejamento urbano (Caldeira, 1997; Maricato, 2011), o crime contra a vida humana e o envolvimento de jovens com o crime, no Brasil, são alguns dos aspectos críticos de uma estrutura social segregacionista e desigual, com claros rebatimentos espaciais. Estudos mais recentes sobre as relações entre pobreza e violência urbana corroboram essa realidade de desigualdades estruturais, segregação e estigmatização da pobreza (Barcellos e Barreto, 2017; Santos et al., 2017).

Os eventos devem, portanto, ser observados e analisados no território, espaço vivido pelo homem e compreendido na totalidade da formação socioespacial, nas dimensões política, socioeconômica e simbólica. Este território usado é caracterizado pelas mais variadas apropriações, produções, ordenamentos e organizações, configurados pelos agentes que o estruturam.

Para Susana Bujulance (2013), a tessitura urbana é elemento crítico para a compreensão da violência. O território urbano é delineado por espaços urbanos descontínuos, separados por barreiras invisíveis ou simbólicas. Nesses territórios fragmentados, moradores de áreas não incluídas no circuito economicamente 
dinâmico e simbolicamente identificador das cidades, deslocam-se com dificuldade por uma cartografia espacial e socialmente cindida, sentem no corpo as tensões cotidianas.

Revelar e desnaturalizar a violência urbana nas cidades latino-americanas é imprescindível para transformá-las. Nas cidades brasileiras, as periferias urbanas, múltiplas e complexas, permanecem caracterizadas pela precariedade de infraestruturas e dificuldade de acesso a equipamentos e serviços urbanos, agravando uma tendência historicamente constituída. Análises no campo da geografia e ciências sociais comprovam a associação entre vulnerabilidades econômicas, sociais e ambientais e o maior risco para a ocorrência de óbitos por homicídio (Lira, 2017; Beato, 2010), agravada pela presença do tráfico de drogas (Corrêa \& Lobo, 2019). A sobreposição de vulnerabilidades marca esses espaços de exclusão, e denuncia a constante tensão da vida que, subitamente, pode ser interrompida.

No Estado de São Paulo, a taxa de homicídio reduziu progressivamente nos últimos dez anos. Adorno e Nery (2019), em análise baseada nas tendências históricas da cidade de São Paulo, ressaltam a heterogeneidade espacial do fenômeno e sua complexa multicausalidade, que envolve fenômenos macrossociais, como aumento da população e da densidade demográfica aliados ao baixo acesso à infraestrutura e serviços urbanos, condições de moradia e gênero, idade e raça; bem como a implementação de políticas na área da segurança pública, incluindo os sistemas de informação. Os mesmos autores, a partir de estudos na área da sociologia urbana, indicam a influência da atuação de fações criminosas, como o Primeiro Comando da Capital sobre as taxas de homicídio, a partir de 2005 e da violência institucional, perpetrada pela polícia, a partir de 2006.

Segundo dados da Fundação SEADE, organizados para a série histórica de 2012 a 2015, a Região Metropolitana do Vale do Paraíba e Litoral Norte (RMVPLN) apresentou, em 2015, o maior índice de óbitos por morte violenta entre as regiões metropolitanas paulistas (17,45 óbitos/100mil habitantes; Estado de SP, 12,04 óbitos/100 mil habitantes). A cidade de São José dos Campos (SJC), embora não apresente as maiores taxas da RMVPLN, tem o maior valor absoluto de óbitos e contribui com $17 \%$ do total dos óbitos por agressão da região.

Totalizando 629.106 habitantes em 2010 e 98,0\% de residentes urbanos, segundo o último Censo Demográfico do IBGE, o município de SJC reúne aproximadamente $29,0 \%$ do total da população urbana da RMVPLN. Respondia, em 2015, por 36,4\% do PIB desta mesma região, movimentado por sua economia dinâmica, com base em serviços e simbolicamente representada pela ciência e tecnologia aeroespacial. A cidade se consolidou como centro regional da RMVPLN e do estado paulista.

Levando em conta essa problemática, uma parceria entre o Comando de Policiamento do Interior e universidades e órgãos de pesquisa da região buscou compreender em que medida o grau de urbanização e o ordenamento territorial e urbano, na cidade sede da RMVPLN, se relaciona aos óbitos por causas violentas. A hipótese é a de que o ordenamento urbano planejado e instituído mantém e agrava condições socioespaciais não equânimes, contribuindo para a construção de territórios de violência.

0 artigo tem como objetivo apresentar e analisar a distribuição dos homicídios dolosos ocorridos em São José dos Campos, SP, nos anos de 2015, 2016 e 2017, considerando o processo de urbanização e a estruturação do espaço urbano, a fim de analisar a relação desses eventos com as condições socioespaciais dos lugares em que ocorrem, com o propósito de subsidiar a discussão política no campo da segurança pública e do planejamento urbano-regional. Está estruturado em quatro seções a partir desta introdução: a primeira detalha a metodologia; a segunda circunstancia o processo de expansão urbana do município; a seção seguinte apresenta e analisa os homicídios dolosos, sua distribuição espacial e relação com a vulnerabilidade socioespacial. Por fim, os achados são discutidos e se apresentam as considerações finais.

\section{Metodologia}

O estudo é descritivo, do tipo ecológico, ou seja, analisa a associação entre dois conjuntos de variáveis sem inferência de correlação causal. Utiliza o procedimento técnico de análise estatística descritiva, o georreferenciamento dos homicídios dolosos ocorridos no município de São José dos Campos em 2015, 
2016 e 2017 e a técnica de análise espacial. 0 período de análise corresponde ao período de parceria entre o Centro de Policiamento do Interior 1, da Polícia Militar (CPI1) e instituições Universitárias e de Pesquisa, sendo parte da estratégia do CPI para a prevenção e enfrentamento de homicídios dolosos. A estratégia continha três eixos: integração das instituições policiais a órgãos públicos, principalmente municipais; integração e trabalho em parceria com as comunidades (criação de conselhos comunitários de segurança e núcleos de vizinhança solidária) e realocação de recursos humanos e materiais da polícia para locais de concentração de crimes. A análise dos crimes envolveu a reformulação, otimização e revisão sistemática dos instrumentos e processos de coleta de dados, aumentando sua confiabilidade. Os dados foram obtidos de fonte secundária (boletim de registro de ocorrências).

\section{Fontes e organização de dados e informações}

Utilizou-se o banco de dados do Setor de Inteligência do CPI 1, que agrega dados de bancos institucionais, sendo o principal o Registro Digital de Ocorrência (BO), documento oficial utilizado pela Polícia Civil e Polícia Militar.

0 processo de registro de dados no BO, no período de estudo, foi aprimorado pelo desenvolvimento de um formulário no formato checklist preenchido pelos policiais militares no local do crime. As informações do BO foram combinadas a outras, disponíveis no banco de dados da Secretaria de Segurança Pública do Estado de São Paulo, bem como informações relatadas no Registro Digital de Ocorrência (RDO/BOPC), Centro de Operações da Polícia Militar (COPOM), PRODESP, INFOSEG e INFOCRIM.

As informações sobre as ocorrências são colhidas no RDO/BOPC e COPOM (que recebe a informação por acionamento telefônico, via sistema 190). Neste artigo selecionaram-se as seguintes categorias de análise provenientes do banco de dados da RDO/BOPC e COPOM: i. local de ocorrência, ii. dados sociodemográficos sobre as vítimas dos crimes, iii. contexto ou motivação do crime. 0 local de ocorrência foi definido pelas coordenadas geográficas; as variáveis sociodemográficas das vítimas incluíram escolaridade, cor e/ou raça e faixa etária.

Os dados obtidos do RDO/BOPC e COPOM foram inseridos em planilha Excel e combinados em tabela única de dados.

\section{Geoprocessamento das informações}

Os casos de homicídios foram transformados em uma tabela de pontos (localização do evento), sendo as coordenadas geográficas (latitude e longitude) o elemento de ligação entre o atributo espacial (polígonos das Áreas de Ponderação do IBGE, de 2010), e o atributo cadastral, composto pelas variáveis selecionadas, proveniente da tabela de dados de homicídios, agregada pelo CPI 1.

Para a espacialização dos dados utilizou-se o software livre Terraview 4.2.2, desenvolvido pelo Instituto Nacional de Pesquisas Espaciais (INPE). Após a espacialização, as camadas de dados foram sobrepostas, proporcionando visões do fenômeno no espaço e no tempo. A escala espacial de análise foi definida pelos limites das Áreas de Ponderação, que dividem o município em treze zonas, e que também foram utilizadas na elaboração dos Documentos de Leitura Técnica do Plano Diretor (LT do PD) do município (IPPLAN, 2017), possibilitando correlações para melhor compreensão dos diferentes contextos sociais e urbanos.

Com ferramentas disponíveis no Terraview, foi gerado um mapa de Kernel, que estima a intensidade de ocorrência de um evento no espaço (estimativa paramétrica). Como resultado, gerou-se uma superfície cujo valor é proporcional à intensidade dos eventos por unidade de área, possibilitando a identificação de Hot Spots (áreas críticas), conglomerados de áreas com altas concentrações do evento (Camargo et al., 2004). Tais áreas indicam que o espaço é uma variável associada à ocorrência dos eventos. 


\section{Caracterização sociodemográfica espacial}

A vulnerabilidade sociodemográfica foi estimada por meio do índice paulista de vulnerabilidade social (IPVS), calculado pela Fundação Seade (2013). Este indicador agrega variáveis das dimensões socioeconômica e demográfica e foi considerado adequado por suas premissas. É construído com base no conceito de vulnerabilidade social, que considera a escassez de recursos (renda) e a capacidade de os indivíduos recrutarem recursos para aproveitar as oportunidades propiciadas pelo Estado, mercado e sociedade para o alcance de seu bem-estar. 0 segundo pressuposto é o de que um indicador de vulnerabilidade deve poder discriminar as diferenças intraurbanas, considerando que a segregação espacial presente nos municípios paulistas contribui para a permanência da desigualdade social.

Duas dimensões constituem o IPVS, socioeconômica e demográfica. A análise dos dados com base no Censo de 2010 classificou os setores censitários do Estado em sete grupos, discriminados na Tabela $1 .^{1}$

Tabela 1 - Grupo IPVS, Classificação de vulnerabilidade e descrição das dimensões socioeconômica e ciclo de vida familiar

\begin{tabular}{llll}
\hline \multirow{2}{*}{ Grupo } & Classificação da & Dimensão & \\
\cline { 2 - 4 } & Vulnerabilidade & Socioeconômica & Ciclo de Vida familiar \\
\hline 1 & Baixíssima & Muito alta & Famílias jovens, adultas e idosas \\
2 & Muito Baixa & Média & Famílias adultas e idosas \\
3 & Baixa & Média & Famílias jovens \\
4 & Média & Baixa & Famílias adultas e idosas \\
5 & Alta & Baixa & Famílias jovens em setores urbanos \\
6 & Muito alta & Baixa & Famílias jovens residentes em aglomerados \\
7 & Muito alta, rurais & Baixa & subnormais \\
\hline
\end{tabular}

Nota: IPVS - Índice Paulista de Vulnerabilidade Social. Fonte: SEADE, 2013.

A vulnerabilidade socioespacial das zonas administrativas foi aferida por método quantitativo e qualitativo. 0 Grupo de IPVS forneceu a base de análise quantitativa (percentual de setores de baixa, média e alta vulnerabilidade em cada uma das treze zonas administrativas que compõem o município). A correlação foi estimada pelo coeficiente de Pearson. O Documento Leitura Técnica do Plano Diretor (LT do PD) (IPPLAN, 2017) forneceu a base qualitativa para diálogos com a produção acadêmica e balizamentos contextuais, não sendo tal documento objeto de análise detalhada. A ênfase da análise foram as informações sobre ocupação histórica, uso e acessibilidade das zonas e presença de equipamentos sociais e de lazer.

\section{São José dos Campos: a cidade se espraia, a segregação socioespacial se concentra}

O crescimento e a transformação da trama urbana de SJC foram impulsionados por políticas públicas de modernização produtiva de base industrial e científico-tecnológica. Esse movimento foi induzido pela inauguração da Rodovia BR-101, Presidente Dutra, em 1950, junto à implantação de instituições e sedes empresariais (públicas e privadas) em sua margem e de uma evolução populacional ascendente. 0 maior impulso à urbanização ocorreu adiante os anos 1950 e, sobretudo, após os decênios de 1970 e 1980, quando SJC se torna uma das localizações preferenciais do interior paulista para a desconcentração produtiva e demográfica a partir da metrópole paulistana. Situado em um importante eixo do mercado nacional, unindo São Paulo ao Rio de Janeiro, o município tem a Via Dutra como principal demarcador do adensamento e expansão de sua estrutura urbana.

1 Dimensões do IPVS: Socioeconômica: inclui as variáveis renda per capita, rendimento médio da mulher responsável pelo domicílio, percentual de domicílios com renda domiciliar per capita de até meio salário mínimo; percentual de domicílios com renda domiciliar de até um quarto do salário mínimo e percentual de pessoas responsáveis pelo domicílio alfabetizadas. Demográfica: percentual de pessoas responsáveis de 15 a 29 anos; percentual de mulheres responsáveis de 10 a 29 anos; idade média das pessoas responsáveis e percentual de crianças de zero a cinco anos de idade. 
Tal processo de produção do tecido urbano, de modo espraiado e fragmentado, com oneração dos custos sociais e de urbanização (Bujulance, 2013), conduziu à estruturação de um espaço urbano com áreas de diferentes graus de acessibilidade, como mostra o mapa de potencial de acessibilidade urbana (Figura 1) para 2015. Observa-se neste mapa, setorizado nas 13 zonas administrativas do município, uma configuração centro/periferia, que combina áreas fisicamente mais integradas à trama urbana (cor vermelha e laranja) nas imediações da Via Dutra, atravessando o município no sentido longitudinal, a áreas de acessibilidade média (cor amarela e verde) no centro antigo e expandido, a oeste da cidade, a leste e a sudoeste.

As formas do tecido urbanizado menos integradas ou potencialmente menos acessíveis, conformam áreas segregadas (cor azul e violeta), a leste e nos extremos norte, sul e oeste da cidade, representando o fenômeno da "periferização", ou "periurbanização", com novas tipologias de ocupação também características do modelo de organização urbana dispersa e fragmentada (Reis Filho, 2006). Essas áreas periféricas se diferenciam qualitativamente. Em direção leste, sul e norte, abrangem majoritariamente espaços residenciais com precariedade de serviços, equipamentos e infraestruturas, enquanto na direção oeste localizam-se espaços de residência de segmentos de alta e média renda, cuja acessibilidade física dada pela distância maior ao centro é relativizada pela maior acessibilidade social.

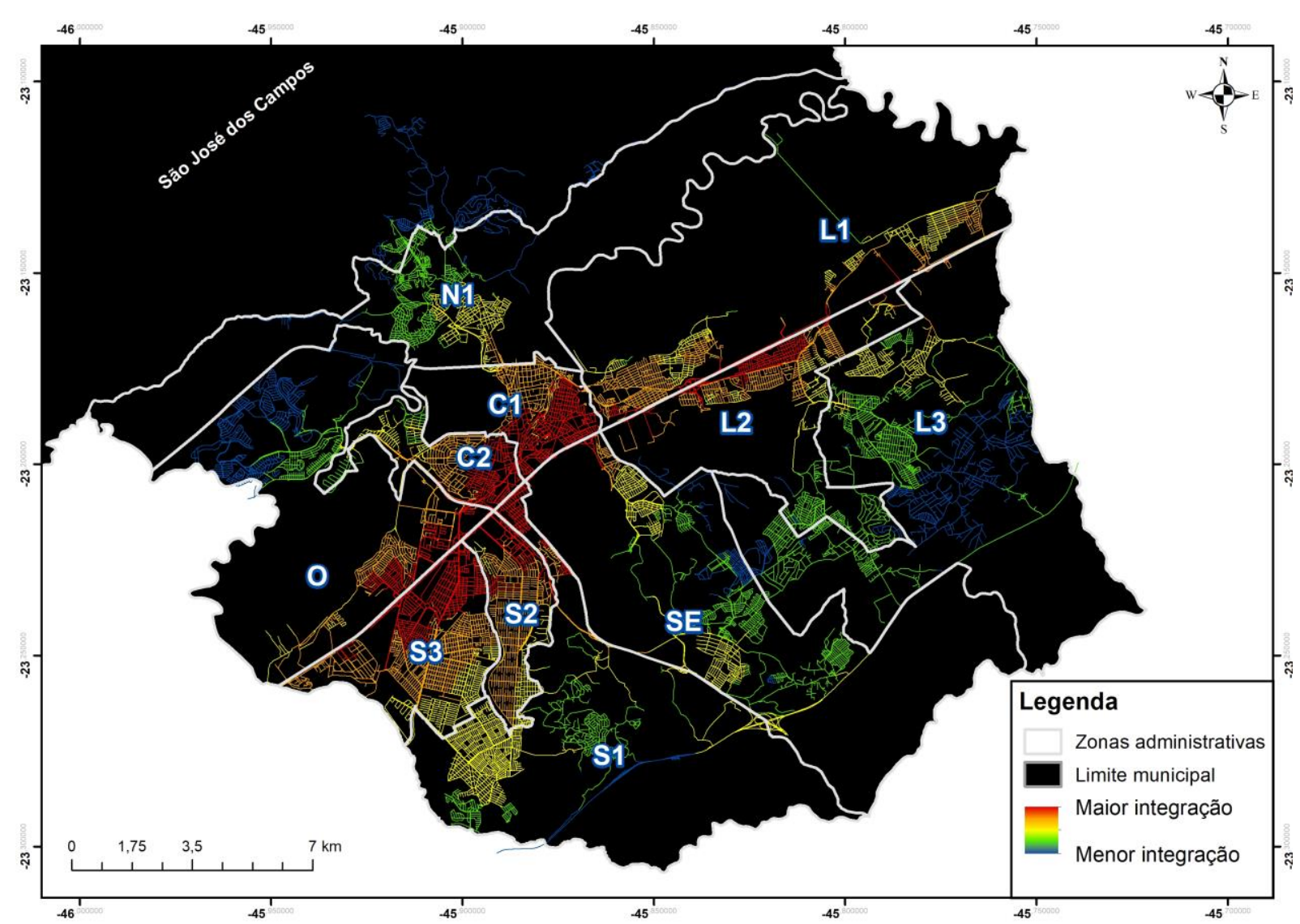

Figura 1 - Potencial de acessibilidade urbana da cidade de São José dos Campos em 2015 com sobreposição às 13 zonas administrativas do município. Legenda: C1 - Centro 1; C2 - Centro 2; N1 - Norte 1; S1 - Sul 1; S2 - Sul2; S3 - Sul 3; L1 - Leste 1; L2 Leste 2; L3 - Leste 3. Fonte: Acervo do Núcleo de Estudos do Espaço Urbano e Regional, PLUR-UNIVAP.

0 padrão de urbanização se consolida pela linearidade da expansão ao longo da Via Dutra, pela centralidade original da cidade na região centro-norte (C1, C2, N1), e pelas novas centralidades constituídas, adiante os decênios de 1970 e 1980, nas regiões sul e oeste da cidade.

Combinando-se ao desenvolvimento histórico e socioeconômico e aos ordenamentos estabelecidos pelos Planos Diretores, a configuração da acessibilidade urbana retrata a condição espacial de zonas diferenciadas. A região sul, mais densa, apresenta piores indicadores sociais, enquanto a oeste, menos densa, apresenta melhores indicadores. A região leste caracteriza-se pela ocupação fragmentada e a clandestinidade e precariedade dos loteamentos, que se multiplicam em direção à Rodovia Carvalho Pinto 
desde início dos anos 1990. A região norte reflete a expansão urbana recente, diferenciando-se da zona leste por ser área de transição urbano-rural e pelo significativo capital ambiental.

Os vetores de expansão urbana na última década reforçam a tendência do espraiamento em direção leste e sudeste do perímetro urbano, indicando um novo paralelismo da estrutura urbana em relação à Rodovia Carvalho Pinto.

Os extremos das regiões Leste e Sudeste apresentaram expressivo crescimento demográfico entre 2000 e 2010, com significativo componente de parcelamentos clandestinos, sem infraestrutura mínima de pavimentação, drenagem e iluminação, em áreas ambientalmente frágeis (PMSJC, 2018). Alvarenga et al. (2018) relacionam este padrão de segregação socioespacial, espraiamento e urbanização periférica à política habitacional do município (Alvarenga et al., 2018). Entre 2013 e 2016, segundo os autores, políticas públicas estaduais e federais possibilitaram a construção de 9.605 habitações sociais.

O Plano Diretor de Desenvolvimento Integrado de SJC (PMSJC, 2018, p. 5) reconhece esse modelo de expansão urbana, apontando a coexistência de "duas realidades urbanas":

\begin{abstract}
Uma área central, compacta, infraestruturada e com bom padrão urbano e a cidade "espraiada e periférica", com bairros irregulares, núcleos informais entremeados por vazios urbanos, menos equipamentos comunitários, maior vulnerabilidade ambiental e áreas de risco, baixa disponibilidade de comércio e serviços e menor oferta de empregos.
\end{abstract}

Como proposta, o Plano apresenta diretrizes para, supostamente, enfrentar o problema da dispersão urbana, como se verá mais adiante.

\title{
Os homicídios dolosos: análise socioespacial
}

Entre 2015 e 2017, 185 homicídios foram registrados, sendo 63 em 2015. Em 2016 nota-se um acréscimo de 20,6\% (76 óbitos), e em 2017 uma redução de 27,0\% quando comparado ao ano de 2015 e 40,0\% quando comparado a 2016 (46 óbitos).

\section{Quem são as vítimas? Caracterização sociodemográfica e motivação dos homicídios}

Dos 185 casos de homicídios registrados nos BOPM, em 142 (76,7\%) foi possível identificar a motivação. Desse total, 28,0\% foram vítimas de conflitos relacionados ao uso e/ou tráfico de entorpecentes (Tabela 2). Do total de vítimas associadas ao tráfico, 85,0\% eram do sexo masculino e 51,0\% estavam na faixa etária entre 15 e 24 anos. Em relação à escolaridade, 51,0\% cursavam o Ensino Fundamental e 2,0\% o Ensino Médio. Ressalte-se que o campo escolaridade não foi preenchido em 34,6\% dos casos registrados, índice elevado e que pode comprometer a interpretação dos dados (Tabela 2).

Em se tratando da cor ou raça, o maior número absoluto de óbitos foi em pessoas da cor branca. A análise das taxas, no entanto, mostra uma taxa de 4,5 óbitos por 100 mil habitantes da cor preta; 3,0 para os pardos e 2,7 para os brancos, o que corresponde à razão de 1,6 óbitos de negros e 1,5 óbitos de pessoas pardas em relação aos brancos (Tabela 2).

Como observado e em concordância com estudos nacionais, as principais vítimas são homens jovens, negros e de baixa instrução (Waiselfisz, 2016; IPPLAN, 2017), e a principal motivação para o crime se relaciona ao uso ou comercialização de drogas. 
Tabela 2 - Caracterização das vítimas de homicídio por faixa etária, sexo, cor/raça, nível de instrução e motivação. São José dos Campos, 2015-2017

\begin{tabular}{|c|c|c|c|c|c|}
\hline Variável & $\mathbf{n}$ & $\%$ & Variável & $\mathbf{n}$ & $\%$ \\
\hline Faixa etária & & & Motivação & & \\
\hline $0-14$ & 7 & 3,8 & Conflitos natureza passional & 15 & 8,2 \\
\hline $15-24$ & 62 & 33,5 & Conflitos em unidade prisional & 2 & 1,1 \\
\hline $25-59$ & 95 & 51,4 & Conflitos do cotidiano & 22 & 12,0 \\
\hline$>60$ & 8 & 4,3 & Conflitos entre familiares & 5 & 2,7 \\
\hline Sem informação & 13 & 7,0 & Indícios de conflitos por drogas & 52 & 28,3 \\
\hline Sexo & & & Indícios outros tipos criminais & 42 & 22,8 \\
\hline Masculino & 159 & 86,0 & Intolerância & 3 & 1,6 \\
\hline Feminino & 22 & 11,9 & Linchamento & 1 & 0,5 \\
\hline \multirow[t]{2}{*}{ Sem informação } & 4 & 2,1 & & & \\
\hline & & & $\begin{array}{l}\text { Sem classificação por } \\
\text { insuficiência dados }\end{array}$ & 43 & 23,4 \\
\hline \multicolumn{6}{|l|}{ Nível instrução } \\
\hline Analfabeto & 5 & 2,7 & & & \\
\hline Fundamental & 70 & 37,8 & & & \\
\hline Médio & 42 & 22,7 & & & \\
\hline Superior & 4 & 2,2 & & & \\
\hline Sem informação & 64 & 34,6 & & & \\
\hline \multicolumn{6}{|l|}{ Cor/Raça* } \\
\hline Branco & 124 & 2,7 & & & \\
\hline Pardo & 41 & 3,0 & & & \\
\hline Negro & 12 & 4,5 & & & \\
\hline Sem informação & 8 & & & & \\
\hline
\end{tabular}

* Por 100 mil habitantes. Fonte: Autores, com dados obtido de: RDO/BOPC e COPOM, Polícia Militar, 2018.

\section{Onde ocorrem os homicídios? Distribuição espacial dos homicídios dolosos}

O mapa de Kernel (Figura 2) ilustra a distribuição espacial dos homicídios dolosos no município de SJC, por ano. Apresenta as áreas de maior densidade de casos como manchas mais escuras (hotspots), conglomerados que correspondem a áreas críticas. A escala de análise foram as zonas administrativas do município (IPPLAN, 2017) (Figura 1). 

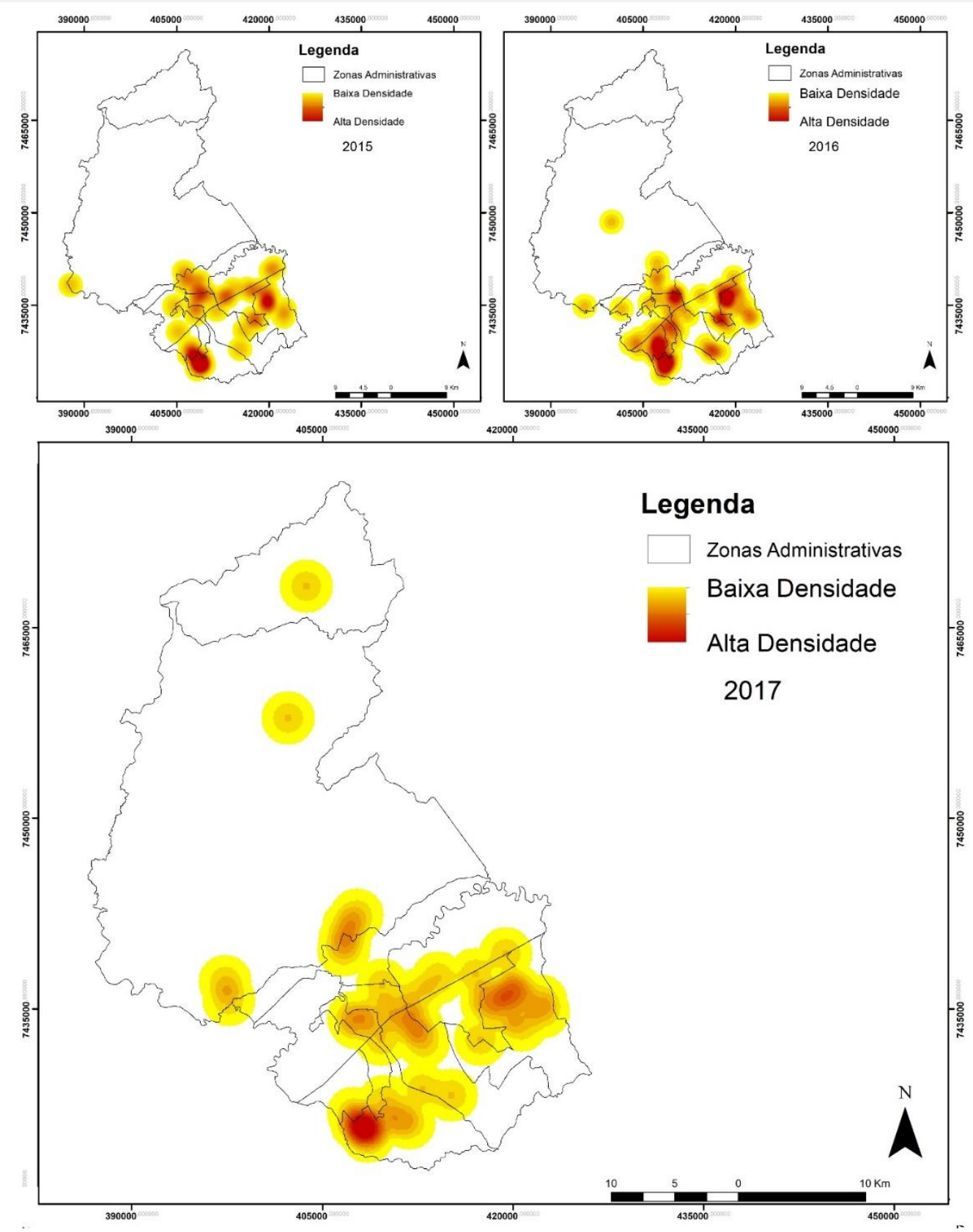

Figura 2 - Densidade dos homicídios na área urbana do município de São José dos Campos; 2015/2016/2017. Fonte: Autores, a partir de dados obtidos dos bancos RDO/BOPC e COPOM.

A dinâmica espacial dos eventos mostra que, em 2015, as ocorrências concentravam-se em três zonas: i. Sul 1, núcleo denso e médio potencial de acessibilidade; ii. Centro 1, núcleo rarefeito e alto potencial de acessibilidade na vizinhança e iii. Leste 3, com núcleo mais denso que a Zona Centro 1, porém mais rarefeito comparado à Zona Sul 1, e baixo potencial de acessibilidade. Observa-se uma conexão entre as Zonas Leste 3 e Centro 1.

Em 2016, ano com acréscimo de 20,6\% na taxa de homicídios, observam-se as mesmas centralidades, porém, com mudança no padrão e comunicação entre as áreas de maior densidade: i. Zona Sul 1: a mancha se amplia e intensifica, passando a abranger a Sul 3 e, com densidade menor, a Sul 2; Zona Centro 1: em relação ao ano de 2015 nota-se maior densidade e a conexão com as Zonas Sul 2 e 3; iii. Zona Leste 3 apresenta maior concentração em comparação ao ano anterior e expansão em direção ao sul da zona. Não se observa a conexão entre as zonas Leste e Centro, porém, aparece, na zona Sudeste, uma mancha de baixa densidade, anteriormente não observada.

Em 2017, embora o número de homicídios tenha reduzido, o padrão se manteve. É evidente a consolidação dos três núcleos - nas zonas Sul 1, Centro 1 e Leste 3 - conectados com um espalhamento 
multilateral, constituindo um cinturão. É perceptível o surgimento de uma mancha, ainda rarefeita, nas zonas Norte 1 e 2.

A espacialização dos homicídios, relacionada aos mapas de acessibilidade urbana (Figura 1) e aos vetores de crescimento urbano, que se direcionam às zonas Leste e Sudeste, com empreendimentos para população de baixa renda (IPPLAN, 2018) apresenta um padrão misto, de "periferização dos homicídios", combinada a um foco central. Estariam as políticas públicas orientadas para enfrentar, nesses espaços, tanto periféricos como centrais, o acúmulo de vulnerabilidades sociais e espaciais, condição de "desvantagens concentradas" (Beato, 2010), em relação à localização espacial de determinados grupos em lugares de rarefeita proteção do Estado? A próxima seção examina essa questão.

\section{Homicídios, vulnerabilidade social e infraestrutura urbana}

Entre os 184 óbitos, 164 (89,1\%) ocorreram em setores censitários com classificação pelo IPVS. Observa-se um gradiente crescente de índice de homicídios (Tabela 3). As menores taxas são encontradas nos setores de baixíssima, muito baixa e baixa vulnerabilidade $(13,76 ; 19,82$ e 27,16 óbitos por 100mil habitantes, respectivamente), atingindo o valor de 44,46 óbitos/ 100 mil habitantes nos setores de média vulnerabilidade e 47,34/100 mil habitantes nos setores de alta vulnerabilidade social. Entre a população de 4.840 pessoas residentes nos setores classificados como de alta vulnerabilidade rural, apenas um caso foi registrado e entre os 7.048 residentes em aglomerados subnormais urbanos, nenhum. Note-se que o Censo de 2010 (IBGE, 2010) registrou, no município, apenas três aglomerados subnormais: Os aglomerados Banhado (Centro 1); Pinheirinho (Sul 1) e Vila Rhodia (Norte 1), em contraste com os dados da NT do PD (IPPLAN, 2017), que identificou um número expressivamente maior de áreas em condições precárias de vida: 43 zonas especiais de interesse social (ZEIS 1), 72,1\% delas na zona Leste 3 e 61 núcleos informais, concentrados nas áreas rurais ao Norte (Norte 2) e ao sul do município (Sul 1).

Tabela 3 - Total de óbitos e índice de homicídios por 100 mil habitantes por classe de vulnerabilidade, medida pelo IPVS. São José dos Campos, 2015 a 2017.

\begin{tabular}{llll}
\hline Classe de Vulnerabilidade & População & $\begin{array}{l}\text { Número de } \\
\text { Homicídios }\end{array}$ & $\begin{array}{l}\text { Índice de Homicídios/100.000 } \\
\text { habitantes }\end{array}$ \\
\hline 1 - Baixíssima vulnerabilidade & 58.143 & 8 & 13,76 \\
2 - Vulnerabilidade muito baixa & 282.543 & 56 & 19,82 \\
3 - Vulnerabilidade baixa & 132.568 & 36 & 27,16 \\
4 - Vulnerabilidade média & 89.975 & 40 & 44,46 \\
5 - Vulnerabilidade alta urbano & 48.586 & 23 & 47,34 \\
6 - Vulnerabilidade alta rural & 4.840 & 1 & 20,66 \\
7 - Vulnerabilidade muito alta & 7.048 & - & - \\
(aglomerado subnormal urbano) & & & \\
\hline
\end{tabular}

Nota: IPVS - índice Paulista de Vulnerabilidade Social. Fonte: Autores a partir de IBGE (2010) e SEADE (2013).

A análise dos setores urbanos mostra que os índices são mais elevados nas Classificações IPVS 4 e 5 (vulnerabilidade média e alta urbano). Ressalte-se, como apresentado na metodologia, que a variável renda diferencia as classificações 4 (média vulnerabilidade) e 3 (baixa vulnerabilidade). Os setores de alta vulnerabilidade rural apresentam baixos índices de homicídio, o que pode evidenciar a dinâmica urbana do evento, relacionado ao conflito por drogas e outros tipos criminais, ou ser um viés dada a menor população residente nessas áreas. A Classe 7, além da menor população, comparada às demais, está sub-representada, incluindo apenas três núcleos, identificados no censo de 2010, em contraste aos 104 núcleos de assentos precários de habitação assinalados na NT do PD (IPPLAN, 2017). Excluindo-se as Classes 6 e 7, o índice de correlação de Pearson alcança 0,9764. 
A análise das zonas administrativas pelo grau de vulnerabilidade, aferido pelo IPVS (Tabela 4), corrobora, no geral, o diagnóstico socioeconômico das zonas administrativas apresentadas na NT do PD (IPPLAN, 2017). Considerando-se o total de homicídios, a distribuição espacial se concentra nas zonas administrativas Sul 1 (19,1\% do total) e Leste 3 (18,5\% do total), seguida da Sul 3 (10,7\% do total) e Leste $2(10,1 \%)$. As maiores taxas de homicídio por 100 mil habitantes estão nas regiões Leste $3(57,72)$ e Sul 1 $(43,78)$, seguidas das zonas Leste $2(39,16)$, Norte $2(38,96)$, Norte $3(34,01)$, Centro $1(31,21)$ e Sudeste $(30,57)$. A pequena população das regiões Norte 2 e 3 pode ter provocado viés na taxa de homicídio; ademais, no Plano Diretor, tais zonas estão classificadas como zonas rurais, sendo que a zona Norte 3 corresponde ao Distrito de Eugênio de Melo, distante da área urbana.

Tabela 4 - Homicídios (total e taxa por 100 mil habitantes) por região, zona administrativa e grau de vulnerabilidade segundo o IPVS, São José dos Campos, 2015 a 2017.

\begin{tabular}{|c|c|c|c|c|c|c|c|c|}
\hline Região & Zona & População & $\begin{array}{l}\text { Homicídios } \\
\text { (n) }\end{array}$ & $\begin{array}{l}\text { Taxa de } \\
\text { Homicídios } \\
\text { (/100 mil } \\
\text { habitantes) }\end{array}$ & $\begin{array}{l}\text { 1 a } 3 \text { - Baixa } \\
\text { Vulnerabilidade } \\
\text { (\% de setores) }\end{array}$ & $\begin{array}{l}4 \text { - Média } \\
\text { Vulnerabilidade } \\
\text { (\% de setores) }\end{array}$ & $\begin{array}{l}5 \text { e } 6 \text { - Alta } \\
\text { Vulnerabilidade } \\
\text { (\% de setores) }\end{array}$ & $\begin{array}{l}7 \text { - Alta } \\
\text { Rural } \\
\text { (\% de } \\
\text { setores) }\end{array}$ \\
\hline \multirow[t]{2}{*}{ Centro } & Centro 1 & 41.654 & 13 & 31,21 & 70,6 & 8,7 & 3,3 & 0 \\
\hline & Centro 2 & 30.461 & 6 & 19,70 & 90,3 & 0,0 & 0,0 & 0 \\
\hline \multirow[t]{3}{*}{ Leste } & Leste 1 & 57.850 & 8 & 13,83 & 84,6 & 5,5 & 2,2 & 0 \\
\hline & Leste 2 & 45.963 & 18 & 39,16 & 78,0 & 5,1 & 6,8 & 0 \\
\hline & Leste 3 & 57.177 & 33 & 57,72 & 45,9 & 23,5 & 24,7 & 0 \\
\hline \multirow[t]{3}{*}{ Sul } & Sul 1 & 77.660 & 34 & 43,78 & 27,1 & 39,2 & 24,3 & 0,9 \\
\hline & Sul 2 & 63.877 & 5 & 7,83 & 79,0 & 1,7 & 0,0 & 0 \\
\hline & Sul 3 & 91.999 & 19 & 20,65 & 89,3 & 1,3 & 1,4 & 0 \\
\hline Oeste & Oeste & 41.163 & 6 & 14,58 & 75,5 & 2,0 & 0,0 & 0 \\
\hline Sudeste & Sudeste & 45.800 & 14 & 30,57 & 60,2 & 23,5 & 8,8 & 0 \\
\hline \multirow[t]{3}{*}{ Norte } & Norte 1 & 54.428 & 14 & 25,72 & 65,4 & 22,6 & 4,8 & 0 \\
\hline & Norte2 & 17.967 & 7 & 38,96 & 39,8 & 11,1 & 6,7 & 0 \\
\hline & Norte 3 & 2.940 & 1 & 34,01 & 60,0 & 20,0 & 20,0 & 0 \\
\hline
\end{tabular}

Fonte: Autores a partir de IBGE (2010) e SEADE (2013).

As zonas administrativas urbanas Sul 1 e Leste 3 apresentam os mais elevados índices de homicídio e o maior percentual de setores censitários em situação de vulnerabilidade: praticamente um quarto da população habita setores de alta vulnerabilidade. A mobilidade é ressaltada como um ponto crítico nessas áreas (IPPLAN, 2017). Na zona Sul 1, pesquisas de movimento pendular mostram que a maior parte dos deslocamentos se realiza dentro da própria região, comprovando a inferência de menores movimentos e fluxos e, portanto, menor acessibilidade urbana relacionada ao desenho do arruamento (Figura 1). Nesta adensada zona, conhecida, pejorativamente, como "fundão da zona sul", a renda média é metade da renda média da cidade e o baixo Gini atesta a uniformidade dessa condição. Os indicadores de renda, analfabetismo e ocupação no mercado de trabalho situam-se abaixo da média do município e há carência de equipamentos sociais. A NT do PD ressalta que as viagens de moradores, majoritariamente a destinos próximos, podem revelar outro tipo de barreira para o acesso a serviços indisponíveis em sua área: "o fato de não circularem pela cidade sinaliza para uma invisível barreira ante a serviços disponíveis em outras regiões" (IPPLAN, 2017, p.144).

A região Leste 3 experimentou expansão significativa entre os censos de 2000 e 2010 (mais de $10 \%$ ao ano). Segundo a LT do PD (IPPLAN, 2017), é uma das zonas mais pobres e precárias do núcleo urbano, com indicadores abaixo do padrão médio da cidade. Destacam-se vários loteamentos irregulares, em regularização ou recentemente regularizados. Apresenta a quarta menor renda média entre as 13 zonas 
administrativas e, assim como na Sul 1, o índice de Gini é baixo. Casas de alvenaria sem revestimento somam quase $20 \%$ dos domicílios, e $21 \%$ possuem esgotamento por fossa rudimentar em $21 \%$ deles. Apenas $2,3 \%$ têm estudo superior completo e dois terços da população está empregado em ocupações elementares. A taxa de desemprego é a maior dentre todas as zonas.

Essas duas zonas refletem a expansão urbana espraiada, impulsionada pelas políticas habitacionais e pela ocupação de áreas na forma de loteamentos, tanto regulares como irregulares, sem infraestrutura urbana adequada. Entre 2006 e 2017, foram implementados no município de SJC um total de 169 loteamentos, sendo 78\% irregulares, 13\% regulares e 7\% em fase de regularização (IPPLAN, 2017). Deste total, 9\% situam-se na zona Sul 1, 32\% na zona Leste 3 e $23 \%$ na zona Norte 2, no perímetro rural do município (IPPLAN, 2017).

A Zona Leste 2, terceira na taxa de homicídios, é "fragilmente desenvolvida" (IPPLAN, 2017, p.159) porém mais heterogênea em comparação às precedentes, como pode se observar pela proporção de setores de baixa, média e alta vulnerabilidade (Tabela 4). Possui características espaciais e ambientais singulares, circunda vasta área ocupada pela Refinaria da Petrobrás e apresenta ativos ambientais e glebas industriais, que contribuem para a ruptura do tecido urbano, como apontado na Figura 1. A LT do PD (IPPLAN, 2017, p. 163) ressalta : "a fragmentação do tecido urbano na região resulta da falta de opção de eixos viários para o acesso à região e distribuição dos fluxos internos"- os equipamentos sociais da região concentram-se na zona Leste 1, e a Via Dutra é uma barreira de acesso para quem habita as zonas Leste 2 e 3 . Embora a renda média seja a mais alta da zona Leste, as ocupações são de baixa qualificação. No núcleo mais antigo (Vista Verde) predominam famílias chefiadas por pessoas mais velhas, nos mais recentes (Campos de São José), pessoas mais novas e de menor renda, evidenciando diferenças históricas na ocupação urbana.

As zonas administrativas Centro 1 e Sudeste tem taxas de homicídios próximas (respectivamente, 31,21 e 30,57/100 mil), menor vulnerabilidade social em relação às zonas Leste 3, Sul 1 e Leste 2, maiores heterogeneidade e acessibilidade urbana. A Centro 1 tem desenvolvimento antigo e abriga bolsões de pobreza (incluindo o Jardim Nova Esperança/Banhado, identificado como aglomerado subnormal no Censo de 2010). A oferta de serviços e comércio é boa, no entanto observa-se precariedade habitacional, com 2,5\% dos domicílios com esgotamento por vala a céu aberto. Já a zona Sudeste, caracterizada por apresentar renda média modesta e população com baixa escolaridade (metade dos moradores não concluiu o ensino fundamental) tem atividades diversificadas (comércio, serviços e indústria de transformação) e habitantes empregados em ocupações elementares e de baixa complexidade. A acessibilidade aos equipamentos sociais é dificultada por barreiras físicas (enclave do Centro Técnico Aeroespacial; empresas aeronáuticas, aeroporto; Rodovias Tamoios e Carvalho Pinto). Em sua área distribuem-se vazios urbanos e se nota isolamento e carência de infraestrutura. Recebeu vários conjuntos residenciais de interesse social, incluindo o Pinheirinho dos Palmares II, com 1.461 unidades residenciais, situado no limite com a Rodovia Carvalho Pinto, inaugurado em 2016. A LT do PD (IPPLAN, 2017) aponta a insuficiência de equipamentos públicos para atender a demanda crescente.

A região Norte 1, com 25,72 óbitos/100 mil habitantes, situa-se na transição urbano-rural (Norte 2 se situa no perímetro rural, Norte 3 corresponde ao Distrito de Eugênio de Melo). A renda média é mais baixa do que a média do município, mas mais alta na região Norte; 95\% dos habitantes são alfabetizados, porém apenas cerca de 7\% têm ensino superior completo; as ocupações são de baixa qualificação; 65\% são nascidos em SJC, e a NT do PD (IPPLAN, 2017) aponta que este fato "indica área pouco atrativa para migrantes e dificuldade de renovação da comunidade, em parte por escassez de loteamentos e empreendimentos". 0 provimento de serviços é adequado, e os habitantes circulam internamente para o acesso aos equipamentos sociais.

A região Sul 3, com 20,65 óbitos/100 mil habitantes, é uma área extensa, com loteamentos antigos, se apresenta semelhante à Sul 2, porém com indicadores mais modestos. A renda média é a quinta maior entre as 13 zonas; há poucas casas em condomínios; mais de 99\% têm acesso a esgoto e água e seu diferencial é a excelente infraestrutura urbana. A população está empregada principalmente em ocupações de nível técnico (IPPLAN, 2017). 
Os demais setores, com taxas inferiores a 20 óbitos/100mil habitantes, se caracterizam pelo baixo percentual de setores de média e alta vulnerabilidade (com exceção da zona Leste 1, mais heterogênea), (Tabela 4) altos níveis de escolaridade e renda, e, em todas, boa provisão de serviços públicos e urbanos (IPPLAN, 2017).

\section{Refletindo sobre os achados: diálogos com instrumentos norteadores e a produção acadêmica}

A despeito dos indicadores sociais e econômicos favoráveis do município de SJC em comparação aos índices nacionais, a caracterização sociodemográfica das vítimas por homicídio se assemelha ao padrão de grandes cidades brasileiras. A maioria das vítimas é jovem, as pessoas de cor e/ou raça negra e baixa escolaridade apresentam maior risco de óbito, e o principal contexto do crime é o consumo ou comércio de drogas, motivação que aumenta a concentração de óbitos na faixa entre 15 e 29 anos. A metodologia não permite aferir relação de causalidade, portanto, tais características sociais e estruturais não devem ser vistas como determinantes, mas, certamente, são condicionantes a serem consideradas.

Os resultados corroboram a produção acadêmica que associa ocorrência de homicídios - como um indicador da violência urbana - ao espaço. Áreas de piores indicadores sociais, aferidas pelo IPVS, localizadas na periferia urbana, com menor potencial de acessibilidade, concentraram os eventos no município de SJC no período analisado. 0 foco na região central, área de maior acessibilidade, se concentra em setores censitários mais vulneráveis, confirmando o padrão de mosaico na tessitura urbana e a dificuldade de análises dicotômicas simplistas do tipo centro/periferia (Adorno \& Nery, 2019). A redução do número absoluto e da taxa de homicídios no período estudado não desconcentrou a distribuição espacial dos eventos, ao contrário, a acentuou, observando-se tendência de comunicação entre as áreas.

Ressalte-se a importância da escala de análise adotada. Neste caso, a delimitação coincidente entre áreas de ponderação (IBGE) e zonas administrativas (PMSJC) permitiu identificar diferenças em zonas urbanas contíguas, como Centro I e 2; e observar pontos luminosos e obscuros, expressão figurativa consagrada por Milton Santos, neste município de alto índice de desenvolvimento humano. No entanto, a análise por setor censitário parece mais acurada para indicar um determinado espaço como de risco para a ocorrência de homicídio, em especial nos setores classificados como IPVS 4, vulnerabilidade média.

As áreas críticas se localizam no tecido periurbano, na franja fragmentada e dispersa da cidade, pontuada por loteamentos irregulares e conjuntos habitacionais de moradias sociais, implementados sem a necessária infraestrutura urbana e rede de serviços sociais. As políticas habitacionais, na RMVPLN, em geral, e no município de SJC, especificamente, seguem o padrão nacional, deslocando as populações para áreas periféricas, o que mantém sua vulnerabilidade pela dificuldade de acesso ao trabalho e equipamentos sociais, além de romper redes sociais (Alvarenga et al., 2018).

Observa-se que o provimento de moradia em áreas de trama urbana rarefeita e sem oferta de equipamentos sociais para populações vulneráveis (famílias chefiadas por mulheres de baixa renda e baixa instrução) contribui para a concentração de desigualdades (Beato, 2010), o que, segundo Lira (2017), aumenta o risco de homicídio, em especial para as populações mais jovens.

A similaridade sociodemográfica e baixa acessibilidade a equipamentos sociais, associadas às ligações menos densas que unem as áreas de concentração dos homicídios, nesse meio urbano desconexo e fragmentado, suscita uma aproximação à noção de território circular de Alain Tarrius (1993). 0 autor estudou o movimento dos migrantes, que constroem, em um espaço fisicamente descontínuo, redes de relações que simultaneamente conectam e modificam pontos identitários. Numa analogia, a população em situação de vulnerabilidade, como migrantes internos, busca seu lugar na cidade: transitam entre as periferias e o centro pobre, transformam pontos de passagem em lugares de vida, mas, na cidade excludente, as redes de relações, trocas e valores construídos os diferenciam dos segmentos sociais privilegiados ("o fundão da zona sul") e, muitas vezes, reproduzem a violência do sistema de segregação socioespacial.

Vera Telles e Hirata (2007, p. 187) lançaram um olhar social para essa trama urbana rarefeita, observando e se detendo nos movimentos e nas relações que ocorrem "nas dobraduras entre o formal e o informal, o legal e o ilegal", bem como nos jogos de poder que nelas se alojam, e no trânsito entre fronteiras 
diversas para "sobreviver na adversidade". Para os autores, as estratégias de sobrevivência das pessoas em situação de vulnerabilidade as levam a contornar os dois riscos concretos enfrentados no cotidiano: o risco da "morte violenta" (p. 188) e o de ser categorizado como aquele que nada possui, alvo de programas sociais. Criam-se territórios identitários e relacionais paralelos, alternativos à exclusão, porém por ela marcados.

Este cenário torna-se mais preocupante com a proposta de ordenamento urbano apresentada no Plano Diretor do Município (PMSJC, 2018). O Plano orienta o adensamento da cidade, a criação de novas centralidades e a comunicação viária entre as regiões e sub-regiões para enfrentar a dispersão urbana, no entanto, as diferentes estratégias do macrozoneamento suscitam incertezas.

O Macrozoneamento urbano delineia três macrozonas: consolidação, estruturação e ocupação controlada (MOC). A primeira contempla as áreas bem supridas de equipamentos e acesso (região Centro, Oeste e zonas Sul 2 e 3) e prioriza a ocupação dos vazios urbanos. A macrozona de estruturação projeta novas centralidades e integração viária, conectando "a cidade contínua e os bairros regulares dispersos" (PMSJC, 2018, p. 5), ou seja, a região sudeste às zonas Leste 2 e 1; a porção norte da zona Sul 1 às áreas centrais; as zonas Oeste, Norte 1 e Centro. A ocupação controlada, por sua vez, localiza-se ao sul do perímetro urbano, abrange o extremo sul das Zonas Sul 1, Sudeste e Leste 3: são as áreas mais vulneráveis, as de maior taxa de homicídios, contém vazios urbanos e se situam em área de potencial valorização imobiliária, à margem da Rodovia Carvalho Pinto. O Plano Diretor define essa zona como constituída por "áreas urbanas periféricas, com pouca oferta de infraestrutura e de equipamentos públicos, cuja ocupação deve ser controlada de forma a conter o espraiamento da malha urbana" (p. 30). As atividades promovidas serão as industriais, de logística e serviço, "em lotes distantes da urbanização consolidada" (p. 30). Embora o Plano ressalte que a regularização fundiária e urbanística dos núcleos existentes está prevista e admita a instalação de usos residenciais, lê-se, nas entrelinhas, a reserva econômica desta área e a inobservância da dinâmica de vida do território, que abriga população em situação de vulnerabilidade, baixa acessibilidade e maior risco para a morte prematura por violência.

\section{À guisa de conclusão}

Os achados evidenciam que, na cidade de SJC, o homicídio, como marcador da violência urbana, no período analisado, ocorre em áreas de maior vulnerabilidade social, atinge a população mais jovem e os residentes em áreas de menor acessibilidade urbana. A relação é complexa e a acessibilidade, embora relacionada ao desenho físico e estrutural da malha urbana, deve ser avaliada nas dimensões econômica e simbólica, a serem exploradas em estudos futuros. O Plano Diretor, ao propor que a ocupação da área periférica ao sul do município seja controlada, mantida apartada do núcleo central e sem infraestrutura de serviços, parece manter o padrão de uma política urbana desvinculada do território usado, o que incorreria no risco de combinar a redução da violência nas áreas de maior acessibilidade, renda e melhores condições de vida à sua manutenção, invisível e concentrada, nas áreas de maior vulnerabilidade socioespacial.

A pesquisa sugere a retroalimentação entre espaço e relações sociais, intermediada pela política pública, na geração e manutenção de territórios de violência. A análise territorial dos homicídios desvela nuances ocultas nas séries temporais em escala municipal, que, neste caso, apresenta tendência de queda. 0 uso potencial dos SIGs para a análise e formulação de políticas públicas é evidente. No entanto, a despeito da ampla oferta e acesso em plataformas livres, esses sistemas têm sido pouco utilizados para informar políticas públicas de segurança. A construção de uma parceria entre a polícia, a universidade e institutos de pesquisa, crescentemente convocados, pelas normativas legais, a desempenhar seu papel social, mostrou ser um caminho promissor. No caso em questão, em encontros periódicos, estratégias de inteligência incluíram o ordenamento territorial como um elemento a ser considerado na construção de uma política pública de segurança. Instrumentos de coleta de dados foram revistos e aprimorados, bancos de dados recompostos, e a ampliação do uso da geotecnologia, testada em um município de grande porte, pode se ampliar para a região em que o município se insere, abrindo a possibilidade de análises comparativas de tendências da manifestação de violência em diferentes cidades, considerando o porte e as relações intermunicipais predominantes. 
Mapas, no entanto, têm vida. A correlação entre dados de vulnerabilidade socioespacial e ocorrência de homicídios, de um lado, desnaturaliza a violência urbana e reafirma, em consonância com estudos na área da segurança pública, planejamento urbano e saúde, a persistência da relação entre iniquidades e acessibilidade urbanas, vulnerabilidade socioeconômica e os homicídios. De outro lado, a análise dos mapas numa perspectiva temporal, ainda que limitada ao curto intervalo de três anos, aponta para um movimento dos pontos de concentração (hotspots) e, desta forma, representa a dinâmica do fenômeno. Postula-se, a partir da observação deste movimento, que haja uma conexão relacional entre as áreas de maior concentração de ocorrências e a composição da trama urbana, por onde circulam as vítimas. 0 crescimento urbano, orientado pelas normativas de planejamento urbano ditadas pelos Planos Diretores, é influenciado por um dinamismo de mercado simultaneamente oculto e onipresente, que cria áreas valorizadas e áreas periféricas, com e sem infraestrutura urbana, simbolicamente inseridas ou deslocadas da representação hegemônica que se constrói sobre as cidades. A noção de território circular, cunhada por Tarrius (1993) e analisada por Telles e Hirata para movimentos migratórios (2007), é uma nova hipótese a ser verificada e estudada em estudos qualitativos sobre os homicídios como evento marcador de violência urbana. A análise de quais conexões, relacionais e simbólicas, se estabelecem entre os territórios de vulnerabilidade por onde se movimentam as manchas de homicídios, ultrapassa o alcance de estudos quantitativos e poderá ser verificada tendo por base a noção de territórios circulares de violência. Políticas públicas, ao desconsiderar esses territórios de vida, provendo moradias desarraigadas da trama e estrutura urbana, promoveriam a criação de um território circular de violência que, física e simbolicamente apartado da cidade, conecta, potencialmente, pela mobilidade e fluidez, conglomerados periféricos, ampliando a vulnerabilidade de quem as habita. Nesses territórios de fragilidade institucional, o tráfico de drogas tem se superposto como um elemento de risco adicional (Corrêa e Lobo, 2019; Adorno e Nery, 2019).

A análise da vulnerabilidade social dos territórios pode orientar políticas públicas, e, nesse sentido, a classificação dos setores e zonas vulneráveis deve ser constantemente revista, dado o dinamismo e mobilidade da população que os habita. As políticas de planejamento urbano dos municípios, especialmente as habitacionais e de segurança pública, devem considerar o território usado e vivido em suas proposições, controlando a dispersão do tecido urbano e prevenindo a configuração de territórios de violência. Espera-se que este trabalho alerte os formuladores de políticas públicas para a importância da análise e formulação integradas de políticas sociais, que considerem os territórios e fluxos de vida e almejem a justiça socioespacial, operando-as como caminho para reduzir a distância física e simbólica entre os territórios incluídos e excluídos da cidade e, consequentemente, a insegurança que acompanha esse padrão de trama urbana.

\section{Referências}

Adorno, S., \& Nery, M. B. (2019). Crime e violências em São Paulo: retrospectiva teórico metodológica, avanços, limites e perspectivas futuras. Cadernos Metrópole, 21(44), 169-194. https://doi.org/10.1590/2236-9996.2019-4408

Alvarenga, D. N., Reschilian, P. R., \& Guerra, R. (2018). Local de moradia e vulnerabilidade social na região metropolitana do Vale do Paraíba e Litoral Norte e em São José dos Campos — SP. Oculum Ensaios, 15(1), 149-169. Recuperado em 22 de fevereiro de 2019 de http://periodicos.puc-campinas.edu.br/seer/index.php/oculum/article/view/3928

Araujo, E. M., Costa, M. C. N, Oliveira, N. F., Santana, F. S., Barreto, M. L., Hogan, V., \& Araújo, T. M. (2010). Distribuição espacial da mortalidade por homicídio e desigualdades sociais segundo a raça/cor em um espaço intra-urbano no Brasil. Rev. Bras., epidemiol., 13(94). Recuperado em 28 de junho de 2021 de https://www.scielo.br/j/rbepid/a/6H3v3PfQzDWhLbZNhYnqpXp/?lang=en

Barcellos, W. S., \& Barreto, A. C. J. (2017). Violência urbana: criminalização da pobreza e a disputa territorial do Tráfico de drogas. Revista Eletrônica de Ciências Sociais, (25), 1-296.

Beato, C. C. (2010). Crime e cidades. Belo Horizonte: Editora UFMG.

Brasil. (2002). Política Nacional da Morbimortalidade por Acidentes e Violências. Portaria n. 344, 19/02/2002.

Briceño-León, R. (2012). La Comprensión de los Homicidios en América Latina: ¿Pobreza o Institucionalidad? Ciência \& Saúde Coletiva, 17(12), 3159-3170. https://doi.org/10.1590/S1413-81232012001200002. 
Bujulance, S. G. (2013). El territorio como base de una violencia espacial. Thémata, (48), 37-48. https://doi.org/10.12795/themata.2013.i48.03

Caldeira, T. P. R. (1997). Enclaves fortificados: a nova segregação urbana. Novos Estudos Cebrap, (47), 155-176. Recuperado em 22 de fevereiro de 2019 de http://reverbenet/cidades/wp-content/uploads/2011/08/Enclavesfortificados_segregacao-urbana.pdf

Camargo, E. C. G, Druck. S. F, \& Câmara. G. (2004). Análise Espacial de Superfície. Recuperado em 22 de fevereiro de 2019 de http://mtc-m12.sid.inpe.br/col/sid.inpe.br/sergio/2004/10.07.14.57/doc/cap3-superficies.pdf

Corrêa, R. S. S., \& Lobo, M. A. A. (2019). Distribuição espacial dos homicídios na cidade de Belém (PA): entre a pobreza/vulnerabilidade social e o tráfico de drogas. Urbe. Revista Brasileira de Gestão Urbana, 11, e20180126. https://doi.org/10.1590/2175-3369.011.e20180126

Fundação Seade (2013). Índice Paulista de Vulnerabilidade Social, Versão 2010. Recuperado em 02 de outubro de 2020 de http://ipvs.seade.gov.br/view/pdf/ipvs/metodologia.pdf

Instituto Brasileiro de Geografia e Estatística. (2010). Censo 2010. Recuperado em 22 de fevereiro de 2019 de https://censo2010.ibge.gov.br

Instituto de Pesquisa Econômica Aplicada. (2018). Atlas da Violência (2018). Recuperado em 22 de fevereiro de 2019 de https://www.ipea.gov.br/portal/images/stories/PDFs/relatorio_institucional/180604_atlas_da_violencia_2018.pdf

Instituto de Pesquisa, Administração e Planejamento. (2017). Leitura técnica do Município para revisão do Plano Diretor. Caderno 7. Regiões urbanas 2017. pp. 131-188. Recuperado em 22 de fevereiro de 2019 de http://planodiretor.sjc.sp.gov.br/estudo-tecnico/14.

Lira, P. S. (2017) Geografia do crime e arquitetura do medo: uma análise dialética da criminalidade violenta e das instâncias urbanas. Rio de Janeiro: Letra Capital, Observatório das Metrópoles.

Madeira, L. M., \& Rodrigues, A. B. (2015). Novas bases para as políticas públicas de segurança no Brasil a partir das práticas do governo federal no período 2003-2011. Revista de Administração Pública, 49(1), 3-21.

Maricato, E. (2011). O impasse da política urbana no Brasil. Petrópolis: Vozes.

Prefeitura Municipal de São José dos Campos. (2018) Plano Diretor de Desenvolvimento Integrado de São José dos Campos. Recuperado em 28 de janeiro de 2020 de: https://www.sjc.sp.gov.br/servicos/urbanismo-e-sustentabilidade/uso-dosolo/plano-diretor-lei-complementar/

Reis Filho, N. G. (2006). Notas sobre urbanização dispersa e novas formas de tecido urbano. São Paulo: Via das Artes.

Santos, A. P., Polidori, M. C., Peres, O. M., \& Saraiva, M. V. (2017). O lugar dos pobres nas cidades: exploração teórica sobre periferização e pobreza na produção do espaço urbano Latino-Americano. Urbe: Revista Brasileira de Gestão Urbana, 9(3), $430-442$.

Silva, B. F. A., Queiroz, B. L., Marinho, F. C., \& Pereira, F. N. A. (2018). Violência urbana e política pública de prevenção: avaliação do Programa Fica Vivo! no estado de Minas Gerais, Brasil. Revista Brasileira de Estudos de População, 35 (2), 1-9. https://doi.org/10.20947/S0102-3098a0059

Soares Filho, A. M. (2011). Vitimização por homicídios segundo características de raça no Brasil. Revista Saúde Pública, 45(4), 745-755. Recuperado em 22 de fevereiro de 2019 de http://www.scielo.br/pdf/rsp/v45n4/2640.pdf

Tarrius, A. (1993). Territoires circulatoires et espaces urbains: Différentiation des groupes migrants. Les Annales de La Recherche Urbane, 59-60, 51-60 (2013).

Telles, V., \& Hirata, D. (2007). Cidade e práticas urbanas: nas fronteiras incertas entre o ilegal, o informal e o ilícito. Estudos Avançados, 21(61), 173-191. Recuperado em 22 de fevereiro de 2019 de http://www.scielo.br/pdf/ea/v21n61/a12v2161.pdf

United Nations Office on Drugs and Crime, UNODC. (2013) Global Study on homicide. Executive Summary. Recuperado em 22 de fevereiro de 2019 de https://www.unodc.org/documents/gsh/pdfs/GLOBAL_HOMICIDE_Report_ExSum.pdf

Waiselfisz, J. J. (2016). Mapa da Violência: homicídios por armas de fogo. Recuperado em 22 de fevereiro de 2019 de https://www.mapadaviolencia.org.br/pdf2016/Mapa2016_armas_web.pdf

Editor: Paulo Nascimento Neto

Recebido: 02 fev. 2020

Aprovado: 17 mar. 2021 